ARTICLE

https://doi.org/10.1057/s41599-019-0293-y

\title{
Antimicrobial resistance, inflammatory responses: a comparative analysis of pathogenicities, knowledge hybrids and the semantics of antibiotic use
}

\author{
Helen Lambert ${ }^{1}$, Meixuan Chen $^{1} \&$ Christie Cabral $^{2}$
}

\begin{abstract}
Antimicrobial resistance is widely recognised as a global threat to human health. This paper explores the mobilisation of biomedical concepts and technologies within local semantic registers and addresses the implications of translation and knowledge complexity for attempts to mitigate the problem of antibiotic resistance. In China, antibiotics are frequently prescribed for common complaints and are widely available without prescription. Drawing on field research in three rural counties of one province, we show that current patterns of antibiotic use are the result of sociocultural, economic and systems drivers within a medical context that draws on precepts from both biomedicine and Chinese medical knowledge. Comparative analysis with European settings suggests that pathogenicity, the set of explanatory frameworks regarding the production of disease, varies socio-temporally in the causal mechanisms that are prioritised. Incorporated within diagnostic strategies that direct treatment towards the bodily response to infection rather than to the infecting pathogen, 'anti-inflammatory medicine' as the popular term for antibiotics in parts of Asia foregrounds physiological process over microbial invasion. We examine the articulation of biomedical knowledge paradigms within a non-Pasteurian milieu in relation to socio-historical process, including hybridisation between ontologically distinct medical traditions and the heterogeneity of scientific knowledge claims that underpin contemporary practices of antibiotic prescribing. We conclude that the concept of inflammation functions as a boundary object which effectively mediates the interfaces between popular knowledges, biomedical sciences and local medical practices. Our analysis may have wide relevance because popular and scientific understandings of inflammation alike draw on metaphors grounded in universal sensory experience that provides a common basis for culturally diverse conceptual elaboration. Situated understandings of inflammation and associated treatment preferences constitute a contextually coherent response to available medical technologies in community health care. Our analysis also calls into question simplistic interpretations of antibiotic use for non-bacterial conditions as deriving from lack of education or public awareness and suggests a need to reconsider current public health knowledge translation strategies.
\end{abstract}

\footnotetext{
${ }^{1}$ Population Health Sciences, Bristol Medical School, University of Bristol, Bristol, UK. ${ }^{2}$ Centre for Academic Primary Care, Population Health Sciences, Bristol Medical School, University of Bristol, Bristol, UK. Correspondence and requests for materials should be addressed to H.L. (email: h.lambert@bristol.ac.uk)
} 


\section{Introduction}

ntimicrobial resistance (AMR) and specifically, resistance to common antibiotics of bacterial pathogens that cause illness in humans, has been identified as a pressing problem for global health and development (World Health Organization, 2015, 2016). Research funders and development agencies acknowledge that AMR is a multifaceted, One Health issue requiring multi-sectoral action and research across the life, medical and social sciences (Jasovský et al., 2016; Mendelson et al., 2016; Das and Horton, 2016; Dar, 2016; Holmes et al., 2016; Laxminarayan et al., 2016; Robinson et al., 2016). The therapeutic use of antibiotic use in human health care is generally agreed to be a key driver of AMR (O'Neill, 2016) and reducing unnecessary or 'inappropriate' (i.e. where not warranted by the presence of bacterial infection) therapeutic use is thus a core component of global and national action plans to tackle AMR, alongside measures to prevent infection and to increase the production of new antibiotics and diagnostic tests for bacterial infection (World Health Organization, 2015).

The concept of 'antibiosis', with its implications for understanding and shaping the character of human-microbe relations as necessarily antagonistic, serves as our point of departure for this case-based enquiry into some embedded assumptions that orient current global health strategies and narratives regarding AMR. ${ }^{1}$ Pathogenicity, or the potential to produce disease, has been characterised, following the political economy of health approach of medical anthropologists, such as Paul Farmer and Merrill Singer, as 'made through the particular configurations of microbes, bodies, environments and so on' (Hinchliffe et al., 2017 , p. 17). The 'anti-biotic', that which is against life, literally encapsulates the biomedical response to the microbial pathogen. However, ecological paradigms that acknowledge the complexity and heterogeneity of interactions between individual organisms, immune responses and environmental conditions in the production of disease are also well established in the biosciences, including biomedicine (Pickstone, 2000), as well as in Asian medical traditions (e.g. Zimmerman, 1982). In biomedicine, which of these dimensions comes to the fore or is subordinated in representations of pathogenicity varies across historical periods (Pickstone, 2000) and biogeographical 'disease situations' (Hinchliffe et al., 2017). Across the multiple sciences that concern themselves with antimicrobial resistance, how AMR should be enfolded within understandings of pathogenicity is currently contested; scientific claims (regarding, for instance, the relative importance of environmental transmission versus antibiotic consumption in driving resistance, or the scale of the role of antibiotics in agriculture, or the significance of probiotics) have yet to be settled (Latour, 1987).

Nevertheless, in the 'Pasteurian world' (Paxson, 2008) of EuroAmerican society that was brought into being by the discovery of microbes (Latour, 1988), and despite the recent emergence of 'post-Pasturian' (Paxson, 2008, p. 15) interest in the microbiome, it is germ theory and the characterisation of organism interaction as antibiosis that dominates social and global health narratives of AMR. At the science-society interface, the complex, unsettled questions and uncertainties entailed in accounting for AMR as phenomenon and process across multiple scientific disciplines are rarely visible. Public-facing explanations present largely unicausal accounts of pathogenicity that centre on the invasive microbial pathogen as increasingly invulnerable threat. Our case study of everyday antibiotic use in an Asian setting reveals a differently configured mobilisation of medical knowledges that, through the anthropological comparative method, enables the articulation of possible alternatives. We build on anthropological evidence on AMR and antibiotics (Rajyowijati and Haak, 2003; Haak and Radyowijati, 2010; Orzech and Nichter, 2008; Chandler and
Hutchison, 2016; Cabral et al., 2014b, 2015) and more broadly on the therapeutic use of pharmaceuticals (Das and Das, 2006; Van Der Geest et al., 1996; Nichter and Vuckovic, 1994; Vuckovic, 1999; Whyte et al., 2003; Van Der Geest and Whyte, 1988), as well as on scholarship in the sociology and history of science and medicine, to demonstrate how patterns of antibiotic prescribing in rural China emerge from certain knowledge-practice configurations in the diagnosis and treatment of illness within the broad ambit of biomedicine as locally practised.

This paper reports on findings from an interdisciplinary collaborative research project investigating drivers of antibiotic use in rural areas of one province in China. There is considerable evidence that antibiotics are overused in the healthcare system (Yin et al., 2013; Li et al., 2012; Zhang et al., 2006; Cui et al., 2017; Jin et al., 2011) of China. Despite government healthcare reforms that have been linked to reductions in prescribing at county and higher level public hospitals (Sun et al., 2015) and a series of policies and initiatives that have begun to modify antimicrobial use (Wang et al., 2016; Zhang et al. 2018), China is estimated to have some of the highest rates of AMR in the world (Cui et al., 2017; Center for Disease Dynamics, 2018). Legislation to prevent over the counter (OTC) sales of antibiotics is in place, but antibiotics can often still be obtained via direct OTC purchasing from pharmacies as well as via medical prescription.

This paper sheds light on current patterns of antibiotic use by exploring the complex relationships between biomedical and other understandings of infection, antibiotic prescribing practices, and the organisation of local health systems. We show how concepts of infection and inflammation are mobilised in rural medical care and reflect on the popular characterisation of antibiotics as 'anti-inflammatory' in relation to measures to rationalise antibiotic prescribing. We then analyse the working of biomedical categories into local semantic registers through processes of hybridisation and differentiation that have been ongoing over the past century. By highlighting the range and heterogeneity of scientific fields that contribute to knowledge of antibiotic action within biomedicine, as well as the semantic complexities entailed in the translation of this knowledge into everyday practice, we provide a novel contribution to the growing body of evidence which problematises simplistic assumptions that prescribing practices which deviate from biomedically orthodox recommendations necessarily result from ignorance or lack of awareness. Our title plays on the biomedical characterisation of the 'inflammatory response', the biochemical reaction to cell injury by bacteria or other causes, as an appropriate descriptor of socio-medical situations that may inadvertently exacerbate the problem of antibiotic resistance. These situations do not, however, result from either wilful or unknowingly inappropriate prescribing or consumption, but from socio-historical processes through which microbial pathogens stand in a different relation to pathogenicity in local biomedicine than in, for example, the UK. Our analysis thus provides both a case study in the construction and contextual variability of biomedical knowledge, and an exemplar of the need to take seriously situated rationalities and context specificity when developing antibiotic stewardship measures (Kakkar et al., 2018).

\section{Study settings and methods}

The wider project from which the material presented here is drawn is an interdisciplinary study to investigate the sociocultural, economic and systems drivers of antibiotic use in rural China and to determine the feasibility of assessing the prevalence of AMR in rural settings (among outpatients presenting to lower level health facilities) through microbiological tests. 
The data we present below were collected between 2017 and 2018 in three counties of a province in eastern China (see Zhao et al. (2019) for full details of the research design). Each field area included one village clinic (the lowest level of the healthcare system), one township health centre (each of which has oversight of 4-7 village clinics in the geographical area covered by the township) and all retail pharmacies (4-8) in each selected township. Health facilities were selected at random from a list provided by the provincial Health Authority. The same procedure was followed to select one village clinic from a list provided by the township health centre management. In this paper, we draw on data collected from patients and health professionals who were recruited in the participating township health centres (3) and village clinics (3). The province is situated in central eastern China and has a population of 68.6 million, of whom $57 \%$ live in rural areas. It is a largely agricultural region with high levels of rural-urban outmigration. Per capita GDP and income rank in the middle (14th) among all provinces in the nation and its social, cultural and economic background is representative of over $80 \%$ of the population in China. In terms of first-time medical care, $62.9 \%$ is at village or community clinics, $17.3 \%$, at township or community health centres and $13.6 \%$ at county level hospitals.

Methods and data collection instruments were piloted in the first field area and modified, where necessary, but since there were no fundamental changes in research design, data from this field area are included in our analysis. Research was then undertaken consecutively in two further field areas (two clinical facilities and all pharmacies per area). In village clinics and township health centres two researchers (a member of academic staff and a graduate student) stationed at each health facility observed clinical consultations over a 4 -month period, recruited consecutive patients who reported symptoms of respiratory tract infection (RTI) or urinary tract infection (UTI) into a microbiological feasibility study for which throat swabs, sputum, or urine samples (depending on presenting symptom) were taken and conducted an exit survey with consenting patients. The observations were undertaken to ensure we had an accurate record of antibiotics prescribed for subsequent comparison with both our microbiological data on antibiotic resistance and with electronic patient records. We also wanted to be able to compare details of actual clinical encounters with doctors' and patients' subsequent accounts. An observational template was developed to assist researchers to record key features of the consultation process, such as whether and which antibiotics were prescribed, who initiated prescribing of antibiotics and the precise terms used to describe them, and how the patient initially presented their health problem to the doctor. The researchers spent one week stationed in each facility before commencing recruitment in order to minimise observer bias. Clinic staff and patients are accustomed to consultations occurring in a semi-public environment (see next section) so the researchers did not attract special attention. Only consultations for which patients gave informed consent are included in our analysis of observational data. The exit survey was constructed by creating a set of short open-ended interview questions, the responses to which were analysed at the end of the pilot phase and transformed into close-ended questions for ease of analysis. The exit survey was administered by a researcher to every enrolled participant immediately following the end of their clinical consultation, with the primary aim of ascertaining knowledge of and attitudes to antibiotics (whether patients knew that they had just been prescribed antibiotics, whether they had previously used antibiotics for this or a previous illness episode in the past year, plans for stopping, storing and sharing antibiotics and familiarity with the concept of antibiotic resistance). Followup in-depth interviews were conducted with a purposive sample of enrolled patients at their homes 1-2 weeks following their visit to the health facility and with the doctors at each healthcare facility towards the end of the study period. The main purpose of follow-up patient interviews was to obtain more detailed narrative information regarding key influences on antibiotic use including the illness, self-diagnosis and related treatment-seeking behaviour, prior use of antibiotics, prompts that led the patient to seek treatment at the relevant health facility and subsequent illness trajectory and treatment decisions. Purposive sampling was used to ensure that our sample included a mix of patients by gender, age, type of reported infection (RTI or UTI) and roughly equal numbers from village clinics and township health centres. Patients were also followed up if interesting information relevant to our study emerged during the exit survey. The purpose of interviewing doctors was to ascertain their perspectives on the drivers of antibiotic use and antimicrobial resistance, including health system incentives and disincentives to prescribe, social influences and their views on patient's needs and preferences regarding antibiotics. A patient record review and comparison with our observational data and a study at retail pharmacies were also carried out.

In this paper, we draw on observational notes of clinical consultations, exit and follow-up interviews with enroled and consenting patients and in-depth interviews with health care facility staff. Table 1 provides a breakdown of the patient sample and Table 2 provides numbers for each dataset by site. Results from the microbiological sampling, pharmacy study and record review are reported elsewhere.

Data were initially recorded onto datasheets either manually or into laptop computers and were then uploaded into an online database at the end of every working day. Quantitative data from the exit survey was subsequently extracted into Microsoft Excel files and descriptive statistical analysis undertaken. Qualitative data was analysed thematically using a data-driven approach, with initial coding categories developed by the whole team of researchers responsible for the social science component of the project, using bilingual (English and Mandarin) transcripts for a small number of interviews and observations of the medical encounter. For each dataset, team members initially developed code labels independently and then developed an agreed bilingual code list through discussion and consensus. These code labels were then applied to all the interview transcripts and observational notes (in Mandarin) in that dataset using NVivo by members of the team who had been responsible for collection of those data and used to produce summary descriptions across transcripts. Themes were developed iteratively from multiple

\begin{tabular}{|llll|}
\hline \multicolumn{3}{l}{ Table $\mathbf{1}$ Recruited patients by site and facility type } \\
Site & Total & Township health centre & Village clinic \\
\hline Site 1 & 160 & 51 & 109 \\
Site 2 & 528 & 375 & 150 \\
Site 3 & 345 & 212 & 133 \\
Total & 1030 & 638 & 392 \\
\hline
\end{tabular}

Table 2 Participants by data type

\begin{tabular}{lllll} 
Dataset & Site 1 & Site 2 & Site 3 & Total \\
\hline Patients observed & 160 & 525 & 345 & 1030 \\
Exit survey & 160 & 525 & 345 & 1030 \\
Patient interviews & 8 & 30 & 21 & 59 \\
Physician interviews & 4 & 10 & 17 & 31 \\
\hline
\end{tabular}


views of the coded data and finalised through discussion and consensus.

\section{The structure and economy of rural health care}

China operates a 'four tier' government healthcare system within which village clinics and township health centres are the lowestlevel health care facilities; above this is the county hospital, and then large public and private hospitals in major urban centres. Individual patients may be referred from village or township facilities to the county hospital, but patients may choose to go directly to the outpatient department of any health facility. Health insurance systems provide limited cover only within the county and province where they are registered as resident and enact a $10-20 \%$ decreasing reimbursement ratio for direct medical expenditures incurred at primary care settings upward (Klotzbucher et al., 2010; Xu et al., 2009).

Each township health centre has both inpatient and outpatient facilities and oversees the public health functions of satellite village clinics, which operate on an outpatient basis only. The number of attending medical staff depends on the population size of each settlement. Township health centre (henceforth THC) doctors have formal medical training (a 5-year university degree) and their salaries and pensions are covered by the county-level government. However, interviews with the THC director and doctors in our first two field sites revealed that $70 \%$ of staff salary comes from government, while the remaining $30 \%$ depends on the financial performance of the individual THC.

Village clinics (officially designated 'health service stations') were incorporated into the national health service in 2008-2010 under medical reforms to integrate rural health management, when private clinics were abolished or converted into these officially sanctioned facilities (Fang, 2014). Many doctors working at today's government village clinics used to practice medicine privately. Some senior staff were originally 'barefoot doctors' who received only basic training but, over time, became private practitioners after the breakdown of the commune system in the early 1980s (Crozier, 1976; Zhang and Unschuld, 2008; Jin et al., 2011). Since 2009 county governments have been training additional staff and rural doctors are now required to possess a medical diploma (zhongzhuan; see Table 3 for a glossary of terms in Chinese and English) gained after 3 year's medical training at a vocational college (Fang, 2014).

Institutionally, village clinics (henceforth $\mathrm{VC}$ ) are managed by the local THC but are financially semi-autonomous. Usually located in an administratively defined village or at a site bordering a couple of administrative villages, $\mathrm{VC}$ buildings and basic equipment are provided by government, but each clinic must generate income to cover overheads and operational costs, from disposable needles to electricity bills. The financial status of village clinic staff is thus much less secure than those at the THC. The village doctors receive no government salary and acquire pension rights only after 15 years of continuous service.

By 2017 when our field research began, the New Rural Cooperative Medical Scheme (NRCMS), launched in 2003, provided almost universal coverage for the agricultural population in the study areas and $87.4 \%$ of the 1030 patients recruited into our study were covered by the NRCMS. The scheme is a mixture of user contribution and government subsidy whereby each member pays an annual fee of 180 Yuan $(£ 20)$, while the provincial and local government contribute another $70-80 \%$, about 450 Yuan

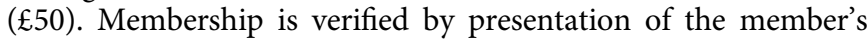
second-generation national ID card which has an integrated circuit chip that can be read automatically by an electronic card reader at any health facility. This technology plays a significant role in generating patient records and accessing reimbursement

\begin{tabular}{|c|c|c|}
\hline Chinese & Pingying & English \\
\hline 村卫生室 & Cun weishengshi & Village clinic (VC) \\
\hline 乡镇卫生院 & $\begin{array}{l}\text { Xiangzheng } \\
\text { weisheng yuan }\end{array}$ & Township Health Centre (THC) \\
\hline 药店 & Yaodian & Pharmacy, medicine shop \\
\hline 内科 & neike & Internal medicine \\
\hline $\begin{array}{l}\text { 中西医结合 } \\
\text { 内科 }\end{array}$ & $\begin{array}{l}\text { zhongxi yi jiehe } \\
\text { neike }\end{array}$ & $\begin{array}{l}\text { Chinese-Western combined internal } \\
\text { medicine }\end{array}$ \\
\hline 儿科 & erke & Paediatrics \\
\hline 抗生素 & Kangsheng su & $\begin{array}{l}\text { Antibiotic, literally "anti-life } \\
\text { element" }\end{array}$ \\
\hline 抗菌药 & kangjun yao & Anti-bacterial medicine \\
\hline 抗微生物药 & $\begin{array}{l}\text { kang weishengwu } \\
\text { yao }\end{array}$ & $\begin{array}{l}\text { Anti-microbe medicine or anti- } \\
\text { microorganism medicine }\end{array}$ \\
\hline 消炎药 & xiaoyan yao & Anti-inflammation medicine \\
\hline & yan & Inflammation \\
\hline 中药 & zhong yao & $\begin{array}{l}\text { Traditional Chinese } \\
\text { Medicine (TCM) }\end{array}$ \\
\hline 西药 & xi yao & Western medicine \\
\hline 感染 & ganran & Infection \\
\hline 咽喉炎 & yanhou yan & Throat inflammation \\
\hline 支气管炎 & zhiqiguan yan & Bronchus inflammation \\
\hline 感冒药 & ganmao yao & Cold remedy \\
\hline 头孢 & toubao & Cephalosporin \\
\hline 黄芪 & huangqi & $\begin{array}{l}\text { Astragalus (a kind of herb used } \\
\text { in TCM) }\end{array}$ \\
\hline 消炎水 & xiaoyan shui & $\begin{array}{l}\text { Anti-inflammation water or water } \\
\text { that eradicates inflammation } \\
\text { (intravenous antibiotic drip) }\end{array}$ \\
\hline 尿路感染 & Naiolu ganran & Urinary tract infection \\
\hline 吊水 & diaoshui & Water for dripstand \\
\hline 尿道炎 & niaodao yan & Urinary tract inflammation \\
\hline 扁桃体炎 & biantaoti yan & Inflamed tonsil \\
\hline 血常规 & Xue changgui & Routine blood test \\
\hline 血象高 & Xuexiang gao & High blood cell (count) \\
\hline 支气管感染 & zhiqiguan ganran & Windpipe infection \\
\hline $\begin{array}{l}\text { 新型农村合 } \\
\text { 作医疗 (新农 }\end{array}$ & Xinxing nongcun & New Rural Cooperative Medical \\
\hline $\begin{array}{l}\text { 作医疗（新农 } \\
\text { 合） }\end{array}$ & hezuo yiliao & Scheme (NRCMS) \\
\hline 中专 & zhongzhuan & Medical diploma \\
\hline
\end{tabular}

through the system. With a national ID card, a proportion of the patient's medical expenses are covered by NRCMS and the rest must be paid out of pocket. The exact proportion depends on factors including whether they are outpatient or inpatient, the type of diagnosis received, and the number of outpatient visits made in the past year.

\section{The consultation process at rural health facilities}

Consultations at both THCs and VCs are offered on a walk-in basis without appointment. At the THC (Weisheng Yuan, literally the Hygiene Courtyard), outpatient consultation rooms are usually the first few rooms on the ground floor of the building complex that makes up the THC, immediately accessible to outpatients as they enter. Labels outside the consultation rooms indicate their focus and patients self-select which one to enter. Most patients with symptoms associated with possible upper respiratory tract infection (RTI) (coughs, colds, sore throat) or UTI come to the "Internal Medicine" (neike 内科), or "Chinese-Western Combined Internal Medicine/Paediatrics" (zhongxi yi jiehe neike/erke 中西医结合内科/儿科) consultation rooms, so this is where our researchers were stationed. The areas for tests and for intravenous (IV) treatment may be located on another floor or in a different building. 
Patients and their companion(s), if any, simply walk into the consultation room and wait to see the doctor, sitting on the wooden bench or standing. At peak hours in the morning it is common to see 6-10 people waiting in the room. Conversations between patient and physician are easily heard by other patients (as well as by our researchers sitting opposite the physician's desk). Occasionally when there are sensitive issues, the physician and a patient leave the room to talk in low voices in the corridor outside to avoid being heard. A single consultation episode typically sees a patient leaving and returning to the consultation room at least twice, to pay for and have tests done if ordered by the doctor before returning with the results, then to pay for and collect medicine before again returning to the doctor for instructions. A patient often has to walk back and forth several times between cashier, in-house pharmacy, test room and consultation room, some on different floors or in different buildings, so that a consultation episode can take the whole morning, though actual physician-patient contact time overall adds up to probably no more than 10 minutes.

Consultation procedures at the VC are more straightforward. The building is a simple single-storey structure, usually with three main rooms. Doctors see patients in a walk-in consultation room, the pharmacist is stationed in the neighbouring room and the IV treatment room is next door. No blood or other diagnostic tests are available. Depending on the size of the village population and the number of long-term residents, the number of doctors varies from one to five. At single-practice clinics, the physician also occupies the various roles of cashier, medicine dispenser/pharmacist, IV treatment administrator, home patient health visitor, electronic record and public health record keeper for the villageregistered population. For clinics with three or more staff members, a general division of labour can be seen, although this is not strictly maintained. An automatic ID card reading machine is connected to the computer and payment is taken in the consultation room.

At the VC, the doctor(s) usually get to know most patients from the village and surrounding areas. They were often born and grew up in the same local area where they-and sometimes their parents or grandparents-have practised medicine for decades. At one of the study VCs, the first thing some male patients would do on arriving at the clinic was to present a cigarette to the doctor, as a socially appropriate gesture of acquaintance and respect. The data presented in the following sections come from observation notes made during everyday consultations in the THC and VC in our field sites.

\section{Antibiotic discourses in health care encounters}

In the rural areas where our research took place, a range of antibiotics are available from both health facilities and retail pharmacies. We found that antibiotics were frequently prescribed to patients presenting with symptoms (cough, sore throat, urination problems) that may indicate a RTI or UTI.

Table 4 shows that nearly $90 \%$ of patients with these conditions who were consecutively recruited into our microbiological study

\begin{tabular}{|llc|}
$\begin{array}{l}\text { Table } 4 \text { Types of treatment received by recruited patients } \\
\text { (directly observed, } \boldsymbol{n}=\mathbf{1 0 3 0} \text { ) }\end{array}$ & & \\
Treatment methods (RTI/UTI) & $\mathbf{N}$ & \% of patients \\
\hline IV antibiotics & 473 & 51.6 \\
Oral antibiotics & 692 & 67.2 \\
Traditional Chinese medicine & 10 & 1.0 \\
Other & 59 & 5.6 \\
IV \& oral antibiotics & 134 & 13.0 \\
IV or oral antibiotics & 916 & 88.9 \\
\hline
\end{tabular}

from six VC and THC, were prescribed antibiotic-containing treatment, through either or both oral or intravenous routes. How 'appropriate' these specific prescriptions were is, as elsewhere, almost impossible to determine. Even where microbiological confirmation is available, tests for RTIs are unreliable; the causative relation between any cultured pathogen and the presence of symptoms is difficult to establish. No directly comparable breakdowns on rates of antibiotic prescribing for RTIs/UTIs are available for China. National reported averages from 2008 for all antibiotic prescriptions indicate that $57 \%$ of prescriptions from primary care facilities contained antimicrobials and 39\% included antimicrobial infusions (Center for Health Statistics and Information, 2008, cited in Cui et al., 2017) A 2010 report based on national surveillance data suggested that on average $60 \%$ of outpatients were prescribed antibiotics (H. Xi et al., 2012, cited in Wang et al., 2017). The latter proportion compares with estimates for the UK that $39-60 \%$ of consultations for RTIs in primary care receive antibiotics (Gulliford et al., 2014). (NICE guidelines recommend that all UTI patients-who comprised only $0.25 \%$ (26/1033) of our sample-receive antibiotics). Clearly rates of antibiotic prescribing should ideally reflect rates of bacterial infection and in this relatively poor, rural population the prevalence of common bacterial infections may well be higher than that seen in more affluent areas, whether in urban China or the UK. However, for almost $90 \%$ of patients reporting RTI symptoms to have an infection of bacterial origin would be unusual. The following analysis unpacks verbal representations of 'antibiotic' that may go some way to explaining the preferment of this form of therapy.

The word 'antibiotic' has several possible renderings in Mandarin (see Table 3). Two formal terms, "kangsheng su" and "kangjun yao" are used in official policy documents relating to antimicrobial use and AMR. Kangsheng su (抗生素 literally “antilife element") is the abbreviation of the literal translation of 'antibiotic' but is rarely used in patient-doctor consultations. Kangjun yao (抗菌药) can be translated as "anti-bacterial medicine" (implicitly referencing biomedicine) and this term again is infrequently used in everyday communication between physicians and patients, though it is the preferred term for medical publications and official guidelines on antibiotics.

In government outpatient clinics the most commonly prescribed antibiotics are Amoxicillin and Cephalosporin. They appear in the Ministry of Health's National List of Essential Medicines (Health Ministry, 2012) under the category of "antimicrobe medicine" or "anti-microorganism medicine" (kang weishengwu yao 抗微生物药). In clinic settings however, cephalosporin and penicillins such as amoxicillin are generally described by both practitioners and patients either by name or as “xiaoyan yao" (消炎药, literally, 'anti-inflammation medicine'). In semi-structured interviews, most healthcare professionals claimed to use "xiaoyan yao" and "kangsheng su" interchangeably. Others said they use the former to enable communication with patients:

“I would say 'xiaoyan yao' (anti-inflammation medicine) to refer to 'kangsheng su' (antibiotics) so that the patients can understand." "I use the term 'kangsheng su' with insiders from our hospital” (THC doctor, site 1).

A doctor at a VC whose main duty is to dispense medicine at the in-house pharmacy said that when talking with other physicians he would use the scientific term kangsheng su (antibiotics), "otherwise I would be laughed at for using the unprofessional term xiaoyan yao (anti-inflammation medicine)." To explain why he uses the latter with patients, he stated that "they do not know", referring to rural residents' "ignorance". This is echoed by another village doctor who commented, "I will say the specific 
medicine name, rather than this type or that type. If you said antibacterial medicine (kangjun yao) or antibiotics (kangsheng su) they would not understand".

These claims are verified by analysis of observational notes of 184 doctor-patient consultations that were recorded in two VC and the four outpatient consultation rooms in three different THC over a total of 12 months ( 4 months in one site). In site 2 THC Room One, where seven physicians rotate attendance in turn, the term "xiaoyan" (anti-inflammation) was recorded 27 times while "yan" (inflammation) was noted 113 times; in Room Two where two physicians rotate in turn for 3-day shifts, "xiaoyan" is recorded 16 times, with "yan" mentioned 55 times. In neither room, by contrast, was the formal term "kangsheng su" recorded at all throughout the observation period. Over the same period in one VC, "kangsheng su" (antibiotics) was spoken once by a patient and only a couple of times by a physician during consultations. In the local institutional and social-economic setting of these rural health facilities, 'antibiotics' (抗生素, kangsheng su) are thus rendered as a form of 'anti-inflammation medicine' (消炎药 xiaoyan yao) by local medical practitioners and their patients; indeed, this term is widely understood in ordinary settings simply to mean 'antibiotic' and is conventionally translated as such. ${ }^{2}$

Infection as inflammation. The literal translation of "xiaoyan yao" or "antibiotics" is "medicine/drug that eradicates or reduces inflammation". It consists of three characters, with the third character yao (药) being a generic term that refers to drug or medicine; for example, "Western medicine" is translated as " $x i$ yao" (西药) and traditional Chinese medicine (TCM) as "zhong yao" (中药). The first two characters “xiaoyan” (消炎) are composed of xiao (消), a verb that can be translated as "to remove, or to eradicate", while yan (炎) is a noun that is generally translated as "inflammation". "Yan", inflammation, denotes a concept that is common to popular understanding, TCM and biomedicine. In Chinese, the character “yan" (炎) is composed of two simple characters for fire (huo 火), readily establishing the connection between "yan" (inflammation) and symptoms of redness, heat and swelling that in Chinese medicine are indicative of a 'hot-natured state' (Otsuka, 1976) and in popular understanding, of 'hot' conditions (Farquhar, 2013); just as for English speakers, 'inflammation' has obvious connotations of redness and heat through its etymological roots in 'catching fire'. "Xiaoyan" in turn is a combined word used as an adjective to mean "antiinflammation" or as a verb to mean "to eradicate inflammation". In biomedical terminology, the character " $y a n$ " is often used as a suffix to a specific body part or body location to indicate the presence of infection (ganran in Chinese 感染) in an equivalent manner to the English suffix “-itis". Thus, yanhou yan (咽喉炎) literally, "throat inflammation", means pharyngitis; zhiqiguan yan (支气管炎), literally, "bronchus inflammation”, is translatable as bronchitis. Yan alone is often used to describe a condition where there is redness, heat and/or swelling such as sore throat or fever, but also where a blood test has indicated a high white blood cell count (see below). ${ }^{3}$

When a patient's symptoms indicate "yan" (inflammation), antibiotics, as "xiaoyan yao", denoting medicines that will remove inflammation, clearly indicate the prospect of effectively treating these symptoms more directly than either "kangsheng $s u$ ” (anti-life element 抗生素) or “kangjun yao" (anti-bacterial medicine 抗菌药). In the next section we summarise three clinical encounters to demonstrate how patients $(\mathrm{P})$ and doctors (D) co-construct the use of antibiotics as appropriate for the treatment of common conditions indicative of inflammation in clinical consultations.
Co-construction of appropriate treatment for common infections. A 65-year-old male (2-1-20171110-01X) came in to a THC to ask for a cold remedy (ganmao yao 感冒药):

P: Help me, prescribe some cold remedy (ganmao yao 感冒药)

D: Cold remedy? For who?

P: For me

D: Prescribe some for cold and some 'to reduce inflammation'? (开点感冒的开点消炎的)

P: Prescribe something to 'reduce inflammation' (开点什么消 炎的)

D: You look, cephalosporin (toubao 头孢)

P: Prescribe more huangqi [a TCM 黄芪]. How many are you prescribing?

D: Two packs of cold remedy; two packs of "xiaoyan yao" (medicine that eradicates inflammation) (感冒药开2盒消炎药开 2盒)

When this patient demands a 'cold remedy' the physician spontaneously also offers antibiotics, which the patient assents to. The physician then specifies that he is prescribing cephalosporin, at which point the patient also requests a type of TCM that is thought to strengthen one's energy $(q i)$. This exchange demonstrates that both physician and patient recognise cephalosporin as a type of antibiotic ("xiaoyan yao", anti-inflammation medicine); that "xiaoyan yao" is useful for treating "cold" (ganmao); and that xiaoyan yao differs from non-antibiotic 'cold remedy' (ganmao yao). Moreover, it illustrates a form of exchange that we found to be common in clinical encounters, whereby doctors spontaneously prescribed antibiotics when presented with symptoms or self-diagnoses indicative of inflammation.

A 17-year-old male patient (2-1-20171106-03Y) came to the general medicine outpatient clinic at the THC and told the attending physician that he had tonsillitis (biantaoti fayan 扁桃 体发炎, lit.“tonsil inflammation”) with pain on swallowing. He said he had taken some amoxicillin and banlan gen (板蓝根 a type of processed TCM for making a drink) the night before, but it was "no use". The doctor did not comment on his selfmedication but examined the patient's throat with the aid of a torch and commented that "the swelling is not so bad". The patient responded that it was sore and asked whether a 'drip of water' (diaoshui, IV treatment-see footnote 2 and Table 4) would be necessary. The doctor replied that a drip was not recommended and said he would prescribe some medicine 'for cold'. The electronic patient record shows the medicines prescribed as two packs of oral amoxicillin (an antibiotic), one pack of qingkailing granule (for making a TCM drink); and one bag of paracetamol pseudoephedrine tablets (for pain relief).

In a third case, a 21-year-old woman (2-1-20171021-01T) came to one of the THCs complaining of a cough. The physician said, "I will dispense you a pack [of medicine] to stop coughing, and a pack of "something that eradicates inflammation" (消炎 的)" and prescribed ambroxol hydrochloride tablets and amoxicillin tablets for oral intake. What appears to be important to patients, confirmed in the patient interviews, is to obtain medicines that perform a specific function in alleviating their symptoms - in this case, antibiotics for reducing or eradicating inflammation. Likewise, residents of a Sichuan village are said to recognise specific drugs they were given by their function rather than their name (Lora-Wainwright, 2005).

In interviews, the doctors in our study sites talked about patient demand as a reason for prescribing antibiotics. Some explained that they find it difficult to refuse patients' requests, either due to the need to maintain a good relationship with patients or for fear of losing patients to other doctors. However, our observations of consultations, as illustrated in the above encounters, demonstrate that the prescribing of antibiotics for conditions characterised by "inflammation" is often initiated by 
doctors rather than patients. One critical reason for these concerns to meet perceived patient expectations is financial, as the "business volume" of patients is related either directly (in the case of village doctors) or indirectly to their income. That patient demand may be a less important driver of prescribing practice than doctors report is supported by evidence from a recent population survey in the same geographical region as our study area. The survey found that contrary to popular assumptions within the medical profession, only a small minority $(0.25 \%)$ of people reported having requested specific prescriptions when consulting a doctor and most expressed no concerns about leaving a consultation without a prescription (Cheng et al., 2018).

Symptoms and technologies in the diagnostic process. The previous section demonstrated that presence of "yan" (inflammation) is usually followed by a prescription for antibiotics (xiaoyan yao). At lower level health facilities in China there is no microbiological support for culturing specimens or for antibiotic sensitivity testing; the THCs have laboratory facilities only for basic urine and blood tests and the VCs have no laboratory, although samples may be sent away to the county hospital in unusual cases. This section explores the interpretation of symptoms and blood test results to inform decision making relating to diagnosis and antibiotic prescribing. It also demonstrates the complex process whereby "yan" (inflammation) and "xiaoyan" (anti-inflammation) have come to occupy a semantic register which encompasses 'infection'.

In both THC and VC, the criteria most frequently used by doctors to indicate "inflammation" (yan) are fever, a red or swollen throat or tonsils, or a high white blood cell count (indicating a strong immune response). Patients attending the THC who complain of cough and a sore or itchy throat are commonly told to obtain a blood test and an X-ray. They usually return to the consultation room with the results within half an hour. The case of a 55-year-old female patient (2-1-20171107$04 \mathrm{~N}$ ) exemplifies this process. She was accompanied by two family members and after an initial brief consultation, the physician ordered a blood test for her. The following conversation was recorded after the patient returned with her blood test result and showed it to the physician:

D: White blood cell is 3 plus (白细胞3个+). This is typical urinary tract infection (尿路感染)

Patient companion (PC): What does that mean?

D: White blood cell [count] indicates there is inflammation (白 细胞说明有炎症).

PC: So that is severe (那很严重)

D: It will be fine with a drip [lit. some 'hanging water' (吊点水 就好了)]. Drink more water and come tomorrow morning without eating anything for another blood test. Take this [hospitalisation note] to the nurse.

In this exchange, the physician diagnoses a UTI based on the blood test result of an elevated white blood cell count, using the term "ganran" (infection). When the patient's family member asks for clarification the physician switches to the term " $y a n$ " (inflammation), describing the problem as "urinary tract inflammation" (niaodao yan 尿道炎), which is construed as serious. The physician then prescribes intravenous (IV) antibiotics and hospitalises the patient. In the electronic record, the physician records the diagnosis as "urinary tract infection" (niaodao ganran) and prescribes three types of antibiotic: ceftriaxone and levofloxacin for intravenous infusion, and erythromycin for oral use, as well as qingkailing tablets (a type of OTC TCM).

Patients as well as doctors interpret symptoms such as redness and swelling as indicative of "yan" (inflammation) and hence as appropriately treated with antibiotics ("xiaoyan yao"), as exemplified by the following consultation at a THC in which a 41-year-old female patient (2-1-20171110-02Y) demands antibiotics for a condition associated with inflammation:

P: Prescribe [me] 'xiaoyan yao' (开消炎药). My throat is swollen (喉咙肿了).

D: (examining throat with a torch) It is swollen.

P: I had it since last night and it doesn't get better with drinking more water.

D: Are you allergic to any medicine?

P: No. Is this tonsil inflamed or throat inflamed? (这是扁桃体 炎还是咽喉炎)

D: Tonsil is not swollen. Throat inflammation. Talk less. (扁桃 体不肿, 咽喉炎, 少讲话)

P: [It has been] over a month

D: Talk less. You must talk less with throat inflammation (咽喉 炎必须少讲话)

The diagnosis recorded electronically was "nose and throat inflammation (yanhou yan 鼻咽炎/咽炎)” and two packs of dirithromycin (an oral antibiotic) and a pack of OTC processed TCM banlangen particles were prescribed.

The role of blood tests as a means of indirectly ascertaining the presence of infections presumed to be bacterial and hence as warranting antibiotics is illustrated by the experience of a 60 year-old woman (2-1-20171023-01T) who complained of a cold (感冒) and fever:

D: [looking at thermometer] Fever, 37.7, low fever. Have you got your ID card?

P: I do

[The doctor then ordered a routine blood test 血常规]

D: Go get a blood test. Come back here afterwards.

[The patient returned in $12 \mathrm{~min}$ with the blood test result]

D: The blood cell is high; your white blood cell is high (血象高 了, 白细胞高了), do you cough?

P: Cough

D: [examines throat] The blood cell is high; it should be bacterial infection (血象高, 应该是细菌感染). Do you have any phlegm?

A diagnosis of bronchitis (lit.'bronchus inflammation 支气管 炎') was recorded and IV cefoxitin (a second-generation cephamycin antibiotic), intravenous vitamin C and pseudoephedrine tablets were prescribed.

Experiences like this indicate to the patient that a blood test can indicate the presence of inflammation (yan), reinforcing an elision between inflammation and infection and providing scientific legitimation to the appropriateness of antibiotics for treating symptoms of inflammation.

\section{Varieties of knowledge in biomedical practice: Pathogenicity and terminology}

The training and qualifications of doctors in village and township health facilities are quite variable, but all those who staffed the clinics where we carried out our study were aware that antibiotics are clinically indicated only for bacterial infections. In interviews, these doctors claimed to use the term "inflammation" (yan) in place of "infection" (ganran) simply in order to be more readily understood by patients. This is illustrated in the above consultation episode $(2-1-20171107-04 \mathrm{~N})$ where the patient's relative asked about the meaning of urinary tract "ganran" (infection) and the doctor switched verbally to "inflammation" (yan), but still entered "infection" (ganran) in the patient's electronic record. However, comparison of other patient records with observed cases and closer examination of biomedical language indicates that this explanation does not adequately account for discrepancies between verbal characterisation and written diagnosis. 
Rather, we found that "infection" and "inflammation" are not systematically distinguished within the biomedical vocabulary used in clinical practice and hence that bacterial infection logically constitutes a form of "inflammation". For example, in the subsequent case above (2-1-20171023-01T), the doctor told the patient, "The blood cell count is high; it should be bacterial infection" but the electronic record states, "bronchus inflammation (zhiqiguan yan 支气管炎)" rather than "bronchus infection". In a similar case (2-1-20171029-02T), the doctor gave a verbal diagnosis of "windpipe infection" (zhiqiguan ganran 支气管感 染)" but recorded a diagnosis of "bronchus inflammation ( $z h i-$ qiguan yan 支气管炎)" in the electronic patient record. The reason for this is that zhiqiguan yan 支气管炎 is in fact the conventional translation of 'bronchitis' in Mandarin and is a standard diagnostic category used in electronic medical records. ${ }^{4}$

Crucially, this is not a simple matter of local misapprehension or mistranslation, for 'inflammation' is not in itself more or less appropriate a descriptor than 'infection' in physiological terms. In conventional northern European biomedical parlance, the word 'inflammation' has come to be used solely to describe discernible conditions of inflammation excluding those caused by bacterial infection, such as osteoarthritic conditions; hence the characterisation of non-antimicrobial medicines such as steroids and ibuprofen as 'anti-inflammatories'. This language convention itself illustrates the special place that the microbe as diseaseproducing has come to occupy in European pathogenicity. However, bacterial infection can (and often does) produce inflammation-just as inflammation can be (but is not always) a consequence of infection.

Indeed, the potential role of inflammation as an immunological indicator of bacterial infection is rapidly gaining prominence and various tests of inflammatory markers, such as C-reactive protein (CRP), are being explored as potential rapid point of care tests for bacterial infection (Aabenhus and Jensen, 2016; Beisel et al., 2016; Haenssgen et al., 2018; Zaw et al., 2018; Little et al., 2013). Our primary focus here is not the use of technologies in healthcare settings, but social analyses that draw on actor network theory to conceptualise testing technologies as evolving along with their local context (Beisel et al., 2016; Haenssgen et al., 2018; see also Chandler et al., 2008) resonate with our observations on how blood tests are used in THCs. CRP is advocated as a measure to reduce 'irrational' antibiotic prescribing in primary care settings by providing a tool for doctors to determine when antibiotics are not needed. It has been shown to reduce prescribing, perhaps not because (as assumed by rapid test developers) it is an accurate marker of bacterial infection, or because (as assumed by general practitioners who use the test) a negative result convinces patients that they do not need antibiotics, but because it influences doctors not to prescribe antibiotics and provides evidence to defend their decision to patients (Tonkin-Crine et al., 2016). In rural China, where (unlike most European primary care settings) rapid point of care blood tests are available in township health facilities, white cell counts are being used for similar social reasons, but for the purpose of justifying prescribing. Whether or not such tests are accurate or appropriate as a decision support tool for antibiotic prescribing, the logic underlying their use for clinical decisionmaking is not inconsistent with immunological understandings of the cellular response to infection. The distinctive difference between these two characterisations of pathogenicity is in their differing emphases on the roles of causative agent and bodily reaction (or 'host response'); in the diagnostic milieu of European primary care, therapeutic decisions focus on causal attribution of the illness to a bacterial or non-bacterial pathogen whereas in these field settings, the primary therapeutic focus is on the inflammatory response.

\section{Pathogenicity and infection: Accommodating Chinese and biomedical knowledges}

Since the early years of the People's Republic, China's health care system has been officially plural. The political history of relations between Chinese traditional medicine and Western biomedicine is a complex one and can only be touched on here; research on Asian medical systems e.g. (Leslie, 1976; Leslie and Young, 1992) has demonstrated how indigenous traditions often become harnessed to wider nationalist ideologies. From the early 20th Century "Western" biomedicine was widely embraced as a tool of scientific progress and modernity (Unschuld, 1992), while Chinese medicine has occupied an ambivalent position as both a 'particularly noxious symbol' (Crozier, 1976, p. 342) of backward tradition and an important marker of cultural identity (see also Farquhar, 1995). Historians of Chinese medicine have traced the contemporary form of TCM to the 1950s, when Chinese medicine was promoted under Mao Zedong through a series of initiatives ultimately aimed at integrating the two traditions (Scheid, 2013, pp. 251-253; Scheid and Hsiang-Lin Lei, 2014). The model that underpins contemporary TCM, "pattern differentiation and treatment determination" (bianzheng lunzhi), sometimes shortened to 'pattern diagnosis', was codified in this period as being definitive of Chinese medical practice. ${ }^{5}$

Historically, boundaries between diseases, symptoms and patterns were not consistently delineated in Chinese medical theory. Within biomedicine too, the advent of germ theory marked an increased emphasis on cause and relatedly, disease specificity. In China infectious diseases (chuanranbing) were officially recognised in the early 20th century following the Manchurian plague epidemic. By implication, the acceptance of germ theory and of microbiological laboratory analysis for diagnostic purposes presented a potential challenge for commensurability between Chinese medical and biomedical nomenclature and the incorporation of germ theory into Chinese medicine. It may have been the biomedical definition of diseases as associated with specific causal pathogens that actually initiated the reconceptualization of Chinese medicine as focusing on 'pattern' rather than 'disease', and on treatment rather than aetiology (Hsiang-Lin Lei, 2014, pp. 168-192). Determining treatment according to 'pattern differentiation' rather than aetiological definition provided a means for Chinese medicine to differentiate itself from biomedicine and to offer practical therapeutics while avoiding confrontation between the distinct and potentially incommensurate ontologies of Chinese medicine and biomedicine.

One of our interviewees, a dual practitioner of TCM and biomedicine, points towards processes of accommodation between Chinese and biomedical approaches to the practice of clinical medicine that support this reading. This VC doctor has TCM training and has been practicing for over 40 years. He is popular locally and dispenses both TCM herbs and biomedicine, including antibiotics. When asked about his diagnostic decisionmaking and selection of medicines, he responded, "If I am going to dispense TCM, I will give a Chinese medical diagnosis; if I am going to dispense Western medicine, I will give a Western medical diagnosis." Field notes on this doctor's consultation practices indicate that for similar symptoms, he would record the diagnosis as "windpipe inflammation" when dispensing TCM and "windpipe infection" when dispensing antibiotics. The same doctor also commented that "TCM can also be used to 'eradicate inflammation' (xiaoyan)". Indeed, currently there is considerable interest among TCM researchers, as well as the educated public, in the potential for identifying "natural antibiotics (tianran kangshengsu 天然抗生素)” from TCM products or herbs (Yuan, 2013).

The effects of what we are describing as accommodation rather than displacement can be seen in the diagnostic processes 
described earlier, while there has been a gradual shift towards prioritising the biomedical diagnosis in medical institutions (Yuan, 2013, pp. 254-255). It is important to note that only a minority of the doctors working in our THC and VC study sites were also trained TCM practitioners. However, Chinese medical precepts such as the recognition of specific symptoms as indicative of 'cool' or 'hot' conditions and the therapeutic use of heating and cooling foods to treat them, are a widespread element of popular culture (Farquhar, 2013). Accordingly, both patients and doctors are broadly familiar with a diagnostic process that treats symptoms as indicative of internal pathological process-in this case, inflammation-rather than of external pathogenic cause (bacterial infection).

\section{Knowledge hybrids and boundary objects}

Globalisation processes bring different cultures of knowledge and practice into close proximity, resulting in borrowing and incorporation of elements between them in a process sometimes described as hybridisation (Holton, 2000; Frank and Stollberg, 2016; Pieterse, 1994; Lock and Nguyen, 2010). In the social sciences, the concept of hybridity has also been deployed productively to highlight knowledge configurations that traverse both social and scientific domains, for example the interweaving of ideas about what constitutes kinship or family with genealogical information in clinical genetics (Gibbon, 2007; see also Wade, 2005). Biomedical science is both global and plural, while the 'indigenisation' of clinical biomedicine into local settings (Kleinman, 1995, p. 24) produces significant diversity of practice, with widely available therapeutic technologies being deployed in different ways (Kleinman, 1995), as the above example of blood tests illustrates.

Sociologists of science have emphasised the 'patchiness' of scientific culture and its heterogenous composition of material, conceptual and social elements in practice (Pickering, 1992). In this case study, the enmeshing of concepts, terms and technologies of 'infection', 'antibiotics' and 'inflammation' - themselves emerging into biomedical practice from the distinct laboratory biosciences of microbiology, pharmacology and immunology with pre-existing local understandings of internal 'heat' - themselves emerging from both codified knowledge contained in Chinese medical texts and popular conceptions of health relating to thermal quality - exemplifies such hybridisation. Over the past half-century biomedical knowledge in this setting has been domesticated, a sometimes contested process by which (in relation to medical traditions becoming integrated into Western context), "the foreign is rendered familiar and palatable to local tastes" (Fadlon, 2004; Cunningham, 1997). In contemporary practice, through a hybrid construct of inflammation-infection these rural doctors draw on popular understandings of pathogenicity, as well as the authority of biomedical science.

Our comparative exploration of pathogenicities and the local language of antibiotics in rural China suggests a historical process of hybridisation and accommodation whereby inflammation (yan 炎) has come to function as a 'boundary object' (Star and Griesemer, 1989) enabling translation between local understandings of person-specific bodily illness, immunological processes and microbiological conceptions of bacterial infection. Initially conceived to explain how people with diverse disciplinary backgrounds and social agendas manage to coordinate consensus in scientific work (Fujimura, 1992), 'boundary objects' may be concepts, material items or methods that facilitate translation across different social worlds. They emerge where the work of multiple groups intersect, not by design but through the characteristics of being adaptable enough to carry different meanings and fulfil different local needs, while having a sufficiently robust structure to be collectively recognisable to all social actors. Once produced, these boundary objects, 'react back upon the social worlds thus linked... reconstituting the very objects of study, as well as the material, conceptual, and social practices that surround them' (Pickering, 1992, p. 13). Seen in this way it is apparent how 'inflammation' does not just reflect, but has come to orient and shape, both local treatment-seeking practices and clinical conventions.

\section{Knowledge, education and social change: Implications for tackling AMR}

We have suggested that the local interpretation of pathogenicity, as foregrounding the treatment of inflammation by 'antiinflammatory' drugs over the 'anti-biotic' extermination of (presumptive) bacterial pathogens, may help to account for the high frequency of resort to antibiotics in treating common RTI and UTI symptoms that we observed in our study clinics. This is just one of many issues contributing to shape current patterns of antibiotic use that for reasons of space we have only been able to touch on here, such as institutional and economic drivers that include systems incentives and payment arrangements within the healthcare system. In addition to these important determinants of antibiotic prescribing are broader social structural influences on antibiotic consumption, including the desire for fast treatment (cf. Vuckovic, 1999) in a setting where agricultural workers can ill afford time off work and high rates of labour migration mean that precious single children are often left in the care of elderly grandparents (Cheng et al., 2018). Many of these determinants have been highlighted elsewhere (e.g. Reynolds and Mckee, 2009; Jin et al., 2011; Sun et al., 2015; Currie et al., 2011), whereas, to our knowledge, antibiotic discourses and their conceptual foundations have not previously been documented.

This analysis has pointed to the semantic complexities entailed in unravelling patterns of antibiotic use in the treatment of common health problems among patients attending rural health facilities in China. Our empirical findings may have limited generalisability to other settings, particularly China's urban environments, where medical specialists are concentrated in large hospitals and sophisticated laboratory support is available to support the treatment of local populations, many of whom are highly educated. However, research showing that education is positively correlated with antibiotic self-medication in China, suggest that the rates of antibiotic use in our study settings cannot simply be attributed to lack of biomedical knowledge or low educational levels. (Bi et al., 2000; Wang et al., 2017; Cheng et al., 2018). Indeed, a cluster randomised survey of 2600 rural residents in 12 counties of eastern China that investigated self-reported health service-seeking and antibiotic consumption, found that knowledge about antibiotics (what pathogens antibiotics are effective for and potential risks of using them) is associated with increased purchasing of over-the-counter antibiotics and with reuse of existing medication from prior illness episodes (Cheng et al., 2018). Our findings regarding local views of antibiotics, including their characterisation as 'anti-inflammatory medicine', the absence of a clear linguistic demarcation between them and other non-antibiotic anti-inflammatories, and their perceived appropriateness in the treatment of common symptoms of viral, as well as bacterial, infection, are also consistent with studies across socioeconomic groups in other provinces of China (Jin et al., 2011).

Although a previous section highlighted processes of knowledge hybridisation that are socio-historically specific to China, research evidence from elsewhere in Asia suggests that our interpretation of the ways in which clinical practice may be inflected by local conditions in the selection of biomedically 
consistent narratives of pathogenicity may have wider relevance. The vernacular characterisation of antibiotics as 'anti-inflammatory' has also been reported from Thailand (Haenssgen et al., 2018; Zaw et al., 2018) and elsewhere; across Asia and the middle East, biomedicine exists together with indigenous codified traditions of medicine that link health with concepts of internal balance and include notions of thermal quality (often characterised broadly as 'humoral'), so it is likely that similar processes of hybridisation with pre-existing medical knowledge have occurred elsewhere. Cross-cultural consistency in local as well as biomedical understandings of inflammation and its symptoms is plausible because they all draw on metaphors that are based in physical as well as cultural experience. Metaphors structure everyday concepts and are reflected in language; sensations of temperature (heat-cold) are fundamental sensory experiences that provide common grounds for culturally diverse conceptual elaboration in both science and everyday life (Lakoff and Johnson, 2003 [1980]).

The World Health Organisation Global Action Plan and linked National Action Plans for tackling antimicrobial resistance emphasise the importance of 'public awareness' and 'education' in reducing inessential use of antibiotics (World Health Organization, 2015; Xiao and Li, 2016). Objective 1 of the Global Action Plan is to, 'Improve awareness and understanding of antimicrobial resistance through effective communication, education and training' and the plan specifies that, 'Steps need to be taken immediately in order to raise awareness of antimicrobial resistance and promote behavioural change, through public communication programmes that target different audiences in human health, animal health and agricultural practices as well as consumers' (WHO, 2015, p. 8). This well-established public health strategy assumes that 'communication, education and training' will 'improve awareness and understanding'; improved awareness and understanding will produce changes in individual behaviour; and individual changes in behaviour will ameliorate the problem.

The emphasis on public education and awareness in national and global AMR policy postulates that patient demand drives antibiotic use and that this demand is excessive. However, we have shown that while local doctors attribute their antibiotic prescribing practices to patient demand, in practice antibiotic prescriptions are often initiated by doctors. The tendency for doctors in general practice to attribute their prescribing of antibiotics for conditions that are not clinically warranted to 'patient demand' has been widely documented elsewhere (Nielsen, 2019; Brookes-Howell et al., 2014; Cabral et al., 2014a; Lucas et al., 2015). In Europe and Scandinavia, patients' desire for reassurance may be (mis)interpreted by doctors as a demand for antibiotics. A UK study of prescribing showed doctors' perceptions of patient pressure to be a consistently stronger predictor of prescribing than patients' actual preferences (Little et al., 2004). Whether or not similar interpretative processes are at play here, the consistency of this finding across diverse cultural and national settings demonstrates how patient treatment preferences do not exist in a vacuum but are constructed dialectically through interaction between health professionals, the institutions through which medicine is delivered, and those who utilise these services.

Our findings indicate that if such demand is present among patients in rural China, it is being co-created by spontaneous prescribing of antibiotics to patients with complaints such as sore throat and cold. Through such encounters, patients and the communities from which they come acquire experiential knowledge that those with medical authority consider antibiotics appropriate for such conditions. This demonstrates the notorious 'fallacy of the empty vessels' (Polgar, 1962) embedded in the assumptions that underpin many health communication and knowledge transfer strategies, for in rural China as elsewhere, the putative targets for education and awareness-raising already possess salient experiential and informal knowledge (and sometimes formal education) that will be mobilised in the interpretation of new information, so that educational interventions which assume 'empty vessels' of ignorance are liable to fail. We have shown that meaningful translation even of the very term 'antibiotic' implicates a local reading of pathogenicity that renders the treatment of symptoms of infection by 'anti-inflammation medicine' appropriate; our analysis suggests that attempts to modify both antibiotic prescribing and consumption practices should, at the very least, take semantics seriously and consider what antibiotics signify locally in designing interventions to modify their use.

Many current education and communication strategies targeting antibiotic use closely resemble the widely critiqued 'deficit model' of the public understanding of science (Irwin and Wynne, 1996) that assumes a unified 'science' which is definitively separated from the social and in which there is a unidirectional transfer of knowledge from learned expert to passive recipient. However, if medical knowledge is actively co-constructed in practice (Lambert and Rose, 1996), with 'loop-back mechanisms' operating between lay and expert, scientific and indigenous, local and cosmopolitan knowledges (Edwards et al., 2007, p. 11), then interventions which take public understanding to be an autonomous and discrete realm from scientific knowledge, or that focus only on individual cognition, are unlikely to succeed in changing practices. Moreover, who counts as an expert depends on social positioning within the health system hierarchy; local doctors who may be regarded as respected authorities by their patients are not always regarded as knowledgeable by their professional counterparts at higher levels of the healthcare system. The appropriate content of education and awareness programmes for both practitioners and patients also requires careful examination, given the complexities of antibiotic use in relation to AMR and (to date) partial and shifting state of scientific knowledges regarding numerous salient issues, from the relative importance of human antibiotic consumption in AMR transmission, to the appropriate duration of antibiotic courses in minimising drug resistance.

Community-wide or societal shifts in behaviour cannot readily be effected through the education of numerous individuals since collective change is a social process, contingent on the specific social, cultural and economic structures upon which behaviour is predicated (Lambert, 2016) and produced through continual interactions between political and professional institutions and civil society actors. The focus on individual behaviour change that currently dominates public health approaches to modifying antibiotic use in order to ameliorate AMR should be complemented by greater attention to dynamic and collective processes of knowledge acquisition, the contingent and plural nature of scientific knowledge, and the semantic and sociocultural, economic and systems influences that shape the actions of health professionals, patients and publics alike.

\section{Data availability}

Following completion of the project in late 2019, all non-sensitive data will be made available on an open access basis through the University of Bristol Data Repository and/or the UK Data Service. Further information is available from the corresponding author on reasonable request.

Received: 3 May 2018 Accepted: 28 May 2019

Published online: 30 July 2019 


\section{Notes}

1 Antibiosis, 'an association between organisms that is injurious to one of them' https:// www.dictionary.com/browse/antibiosis); Anti-, 'opposite, against, in exchange, instead, representing, rivalling,stimulating'; biotic, 'Of animal life; vital' (Oxford English Dictionary 1971).

2 In an account of 'over-prescribing' for colds as common in a village of Sichuang Province, some prescribed pills are recognised by villagers as xiaoyan yao (消炎药) which the author translates, tellingly, as 'medicine for minor infections' (LoraWainwright, 2005, p. 480).

3 A related phrase is xiaoyan shui (消炎水), “water that eradicates inflammation” or "anti-inflammation water", used by patients to refer to antibiotics that are administered intravenously. The institutional and popular preferment of intravenous (IV) treatment is signified by the inclusion in every clinic of a dedicated infusion room for giving IV treatment to outpatients. The importance of this kind of medical intervention may be traced back to its introduction by barefoot doctors with limited medical training in the 1950s (Li et al., 2012; Huang, 2014), but for reasons of space we do not address the specific use of IV antibiotics in this paper.

4 We are grateful to an anonymous reviewer for this observation.

5 In this approach, the physician identifies relevant symptoms and signs as being indicative of specific clinical patterns, or diagnoses, which can then be used to guide treatment strategies. These distinctive patterns can be regarded as similar to syndromes in biomedicine but rather than defining a disease, they enable the practitioner to pinpoint the underlying pathological processes of qi (energy) transformation that give rise to the identified pattern of symptoms at the point of consultation (Scheid, 2013, p. 253).

\section{References}

Aabenhus R, Jensen J-U (2016) Biomarker-guided antibiotic use in primary care in resource-constrained environments. Lancet Glob Health 4:e586-e587

Beisel U, Umlauf R, Hutchinson E, Chandler CI (2016) The complexities of simple technologies: re-imagining the role of rapid diagnostic tests in malaria control efforts. Malar J 15:64

Bi P, Tong S, Parton KA (2000) Family self-medication and antibiotics abuse for children and juveniles in a Chinese city. Soc Sci Med 50:1445-1450

Brookes-Howell L, Wood F, Verheij T, Prout H, Cooper L, Hood K, Melbye H, Torres A, Godycki-Cwirko M, Fernandez-Vandellos P, Ystgaard MF, Falk Taksdal T, Krawczyk J, Butler CC (2014) Trust, openness and continuity of care influence acceptance of antibiotics for children with respiratory tract infections: a four country qualitative study. Fam Pract 31:102-110

Cabral C, Horwood J, Hay A, Lucas P (2014a) How communication affects prescription decisions in consultations for acute illness in children: a systematic review and meta-ethnography. BMC Fam Pract 15:63

Cabral C, Ingram J, Hay AD, Horwood J (2014b) “They just say everything's a virus"-parent's judgment of the credibility of clinician communication in primary care consultations for respiratory tract infections in children: a qualitative study. Patient Educ Couns 95:248-253

Cabral C, Lucas PJ, Ingram J, Hay AD, Horwood J (2015) “It's safer to ..." parent consulting and clinician antibiotic prescribing decisions for children with respiratory tract infections: an analysis across four qualitative studies. Soc Sci Med 136-137:156-164

Center for Disease Dynamics, E. a. P. (2018) ResistanceMap: antibiotic resistance of Escherichia coli in China

Center for Health Statistics and Information (2008) Research on health service of primary health care facilities in China. In: Health MO (ed.) China Medical Union University Publishing House, Beijing

Chandler C, Hutchison C (2016). AMR and anthropology. In: Lambert H (ed.) ESRC research brief for AMR research champion. University of Bristol. http://www.bristol.ac.uk/media-library/sites/social-community-medicine/ documents/social-science-andamr/Anthropology\&AMR_02082016.pdf

Chandler C, Jones C, Boniface G, Juma K, Reyburn H, Whitty C (2008) Guidelines and mindlines: why do clinical staff over-diagnose malaria in Tanzania? A qualitative study. Malar J 7:53

Cheng J, Coope C, Chai J, Oliver I, Kessel A, Wang D, Sun Y (2018) Knowledge and behaviors in relation to antibiotic use among rural residents in Anhui, China. Pharmacoepidemiol Drug Saf 27:652-659

Crozier R (1976) The ideology of medical revivalism in modern China. In: Leslie C (ed.) Asian medical systems. University of California Press, Berkeley \& Los Angeles

Cui D, Liu XL, Hawkey P, Li H, Wang Q, Mao ZF, Sun J (2017) Use of and microbial resistance to antibiotics in China: a path to reducing antimicrobial resistance. J Int Med Res 45:1768-1778

Cunningham AAB (ed.) (1997) Western medicine as contested knowledge. Manchester University Press, Manchester

Currie J, Lin W, Zhang W (2011) Patient knowledge and antibiotic abuse: evidence from an audit study in China. J Health Econ 30:933-49

Dar OEA (2016) Exploring the evidence base fo national and regional policy interventions to combat resistance. Lancet 387:285-295
Das P, Horton R (2016) Antibiotics: achieving the balance between access and excess. Lancet 387:102-104

Das V, Das R (2006) Urban health and pharmaceutical consumption in Delhi, India. J Biosoc Sci 38:69-82

Edwards J, Harvey P, Wade P (2007) Introduction: epistemologies in practice. In Edwards J, Harvey P, Wade P (ed.) Anthropology \& science: epistemologies in practice. Berg, Oxford \& New York, NY

Fadlon J (2004) Meridians, chakras and psycho-neuro-immunology: the dematerializing body and the domestication of alternative medicine. Body Soc 10:69-86

Fang Z (2014) Barefoot doctors and the provision of rural health care. In: Andrews BB, Mary B (ed.) Medical transitions in twentieth-century China. Indiana University Press, Bloomington \& Indianapolis

Farquhar J (2013) Chinese medicine as popular knowledge in urban China. In: Hinrichs TJBL (ed.) Chinese medicine and healing: an illustrated history. The Belknap Press of Harvard University Press, Cambridge

Farquhar J (1995) Re-writing traditional medicine in post-Maoist China. In: Bates $\mathrm{D}$ (ed.) Knowledge and the scholarly medical traditions. Cambridge University Press, Cambridge. p. 251-276

Frank R, Stollberg G (2016) Conceptualizing hybridization. Int Sociol 19:71-88

Fujimura J (1992) Crafting science: standardized packages, boundary objects, and "translation". In: Pickering A (ed.) Science as practice and culture. University of Chicago Press, Chicago

Gibbon S (2007) Genealogical hybridities: the making and unmaking of blood relatives and predictive knowledge in breast cancer genetics. In: Edwards J Harvey P, Wade P (ed.) Anthropology \& science: Epistemologies in practice. Berg, Oxford \& New York, NY

Gulliford MC, Dregan A, Moore MV, Ashworth M, Staa T, Mccann G, Charlton I Yardley L, Little P, Mcdermott L (2014) Continued high rates of antibiotic prescribing to adults with respiratory tract infection: survey of $568 \mathrm{UK}$ general practices. BMJ Open 4:e06245

Xi H, Y. X, D. Z, F. W, Y. N, J. S, Al. E (2012) CHINET 2010 surveillance of antibiotic resistance in Acinetobacter baumannii in China. Chin J Infect Chemother 2:006

Haak H, Radyowijati A (2010) Determinants of antimicrobial use: poorly understood, poorly researched. In: Sosa A, B. D, Amábile-Cuevas C, Hsueh P, Kariuki S, Okeke I (ed.) Antimicrobial resistance in developing countries. Springer, New York, NY

Haenssgen M, Charoenboon N, Althaus T, Greer R, Intralawan D, Lubell Y (2018) The social role of C-reactive protein point-of-care testing to guide antibiotic prescription in Northern Thailand. Soc Sci Med 202:1-12

Health Ministry C (2012) The National List of Essential Medicine. Health Ministry of People's Republic of China, Beijing

Hinchliffe S, Bingham N, Allen J, Carter S (2017) Pathological lives: disease, space and biopolitics. Wiley Blackwell, Chichester

Holmes AH, Moore LSP, Sundsfjord A, Steinbakk M, Regmi S, Karkey A, Guerin PJ, Piddock LJV (2016) Understanding the mechanisms and drivers of antimicrobial resistance. Lancet 387:176-87

Holton R (2000) Globalization's cultural consequences. Ann Am Acad Polit Soc Sci 570:140-152

Hsiang-Lin Lei S (2014) Neither donkey nor horse: Medicine in the struggle over China's modernity. University of Chicago Press, Chicago

Huang P (2014) Doctor-patient relationship and antibiotics abuse. M.Sc., Qinghua University, Beijing

Irwin A, Wynne B (eds) (1996) Misunderstanding science?: the public reconstruction of science and technology. Cambridge University Press, Cambridge

Jasovský DA, Littmann J, Zorzet A, Cars O (2016) Antimicrobial resistance-a threat to the world's sustainable development. Upsala J Med Sci 121:159-164

Jin C, Ely A, Fang L, Liang X (2011) Framing a global health risk from the bottomup: user perceptions and practices around antibiotics in four villages in China. Health Risk Soc 13:433-449

Kakkar M, Chatterjee P, Chauhan AS, Grace D, Lindahl J, Beeche A, Jing F, Chotinan S (2018) Antimicrobial resistance in South East Asia: time to ask the right questions. Glob Health Action, 11:1-5

Kleinman A (1995) Writing at the margin: discourse between anthropology and medicine. University of California Press, Berkeley, Los Angeles \& London

Klotzbucher S, Lassig P, Jiangmei Q, Weigelin-Schwiedrzik S (2010) What is new in the "New Rural Co-operative Medical System"? An assessment in one Kazak County of the Xinjiang Uyghur Autonomous Region. China Q 201:38-57

Lakoff G \& Johnson M 2003 (1980) Metaphors we live by. University of Chicago Press, Chicago

Lambert H (2016) Measurement, modification and transferability: challenges in the evaluation of complex interventions. In: Bell SAP (ed.) Evaluation in health and social development: interpretive and ethnographic perspectives. Routledge, London \& New York, NY 
Lambert H, Rose H (1996) Disembodied knowledge? Making sense of medical science. In: Irwin AWB (ed.) Misunderstanding science?: The public reconstruction of science and technology. Cambridge University Press, Cambridge Latour B (1987) Science in action. Harvard University Press, Cambridge MA

Latour B (1988) The pasteurization of France. Harvard University Press, Cambridge, MA, London

Laxminarayan R, Matsoso P, Pant S, Brower C, Røttingen J-A, Klugman K, Davies S (2016) Access to effective antimicrobials: a worldwide challenge. Lancet 387:168-175

Leslie C (1976) Asian medical systems. University of California Press, Berkeley \& Los Angeles

Leslie C, Young A (ed.) (1992) Paths to Asian medical knowledge. University of California Press, Berkeley, Los Angeles \& Oxford

Li Y, Xu J, Wang F, Wang B, Liu L, Hou W, Fan H, Tong Y, Zhang J, Lu Z (2012) Overprescribing in China, driven by financial incentives, results in very high use of antibiotics, injections, and corticosteroids. Health Aff 31:1075-1082

Little P, Dorward M, Warner G, Stephens K, Senior J, Moore M (2004) Importance of patient pressure and perceived pressure and perceived medical need for investigations, referral, and prescribing in primary care: nested observational study. BMJ 328:444

Little P, Stuart B, Francis N, Douglas E, Tonkin-Crine S, Anthierens S, Cals JW, Melbye H, Santer M, Moore M, Coenen S, Butler C, Hood K, Kelly M, Godycki-Cwirko M, Mierzecki A, Torres A, Llor C, Davies M, Mullee M, O'reilly G, Van Der Velden A, Geraghty AW, Goossens H, Verheij T, Yardley L, Consortium, G. (2013) Effects of internet-based training on antibiotic prescribing rates for acute respiratory-tract infections: a multinational, cluster, randomised, factorial, controlled trial. Lancet 382:1175-82

Lock MM, Nguyen V-K (2010) An anthropology of biomedicine. Wiley-Blackwell, Chichester, West Sussex

Lora-Wainwright A (2005) Valorising local resources: barefoot doctors and bone manipulation in rural Langzhong, Sichuan Province, PRC. Asian Med 1:470-489

Lucas PJ, Cabral C, Hay AD, Horwood J (2015) A systematic review of parent and clinician views and perceptions that influence prescribing decisions in relation to acute childhood infections in primary care. Scand J Prim Health Care 33:11-20

Mendelson M, Rottingen JA, Gopinathan U, Hamer DH, Wertheim H, Basnyat B, Butler C, Tomson G, Balasegaram M (2016) Maximising access to achieve appropriate human antimicrobial use in low-income and middle-income countries. Lancet 387:188-198

Nichter M, Vuckovic N (1994) Agenda for an anthropology of pharmaceutical practice. SW Sci Med 39:1509-1525

Nielsen S (2019) Dealing with explicit patient demands for antibiotics in a clinical setting. In: Jensen C, Nielsen S, Fynbo L (ed.) Risking antimicrobial resistance: a collection of one-health studies of antibiotics and its social and health consequences. Palgrave Macmillan, Cham, Switzerland

O’Neill J (2016). Tackling drug-resistant infections globally: final report and recommendations. The Review on Antimicrobial Resistance

Orzech KM, Nichter M (2008) From resilience to resistance: political ecological lessons from antibiotic and pesticide resistance. Annu Rev Anthropol $37: 267-282$

Otsuka Y (1976) Chinese traditional medicine in Japan. In: Leslie C (ed.) Asian medical systems. University of California Press, Berkeley \& Los Angeles

Paxson H (2008) Post-Pasteurian cultures: the microbiopolitics of raw-milk cheese in the United States. Cult Anthropol 23:15-47

Pickering A (ed.) (1992) Science and practice and culture. University of Chicago Press, Chicago, London

Pickstone J (2000) Ways of knowing: a new history of science, technology and medicine. Manchester University Press, Manchester

Pieterse JN (1994) Globalisation as hybridisation. Int Sociol 9:161-184

Polgar S (1962) Health and human behavior: areas of interest common to the social and medical sciences. Curr Anthropol 3:159-205

Rajyowijati A, Haak H (2003) Improving antibiotic use in low-income countries: an overview of evidence on determinants. Soc Sci Med 57:733-744

Reynolds L, Mckee M (2009) Factors influencing antibiotic prescribing in China: an exploratory analysis. Health Policy 90:32-36

Robinson TP, Bu DP, Carrique-Mas J, Fevre EM, Gilbert M, Grace D, Hay SI, Jiwakanon J, Kakkar M, Kariuki S, Laxminarayan R, Lubroth J, Magnusson U, Thi Ngoc P, Van Boekel TP, Woolhouse MEJ (2016) Antibiotic resistance is the quintessential One Health issue. Trans $\mathrm{R}$ Soc Trop Med Hyg 110:377-380

Scheid V (2013) The people's republic of China. In: Hinrichs TJLL (ed.) Chinese medicine and healing: An illustrated history. The Belknap Press of Harvard University Press, Cambridge

Scheid V, Hsiang-Lin Lei S (2014) The institutionalization of Chinese medicine. In: Andrews BB, Mary B (ed.) Medical transitions in twentieth-century China. Indiana University Press, Bloomington \& Indianapolis
Star S, Griesemer J (1989) Institutional ecology, 'Translations' and boundary objects: amateurs and professionals in Berkeley's Museum of Vertebrate Zoology, 1907-39. Soc Stud Sci 19:387-420

Sun Q, Dyar OJ, Zhao L, Tomson G, Nilsson LE, Grape M, Song Y, Yan L, Lundborg CS (2015) Overuse of antibiotics for the common cold-attitudes and behaviors among doctors in rural areas of Shandong Province, China BMC Pharmacol Toxicol 16:6

Tonkin-Crine S, Anthierens S, Hood K, Yardley L, Cals JW, Francis NA, Coenen S, Van Der Velden AW, Godycki-Cwirko M, Llor C, Butler CC Verheij TJ, Goossens H, Little P, Consortium, G. I. C. (2016) Discrepancies between qualitative and quantitative evaluation of randomised controlled trial results: achieving clarity through mixed methods triangulation. Implement Sci 11:66

Unschuld P (1992) Epistemological issues and changing legitimation: traditional Chinese medicine in the twentieth century. In: Leslie C, Young A (ed.) Paths to Asian medical knowledge. University of California Press, Berkeley

Van Der Geest S, Whyte SR (eds) (1988) The context of medicines in developing countries: studies in pharmaceutical anthropology. Springer, Netherlands

Van Der Geest S, Whyte SR, Hardon A (1996) The anthropology of pharmaceuticals: a biographical approach. Annu Rev Anthropol 25:153-178

Vuckovic N (1999) Fast relief: buying time with medications. Med Anthropol Q 13:51-68

Wade P (2005) Hybridity theory and kinship thinking. Cult Stud 19:602-621

Wang L, Zhang X, Liang X, Li W, Zhang X, Liang X, Bloom G (2016) Addressing antimicrobial resistance in China: policy implementation in a complex context. Glob Health 12:no pagination

Wang X, P. D, Wang W, Xu Y, Zhou X, Hesketh T (2017) Massive misuse of antibiotics by university students in all regions of China: implications for national policy. Int J Antimicrob Agents 50:441-446

Whyte SR, Van Der Geest S, Hardon A (2003) Social lives of medicines. Cambridge University Press, Cambridge

World Health Organization (2015) Global action plan on antimicrobial resistance World Health Organisation, Geneva, Switzerland

World Health Organization (2016) At UN, global leaders commit to act on antimicrobial resistance.

Xiao Y, Li L (2016) China's national plan to combat antimicrobial resistance Lancet Infect Dis 16:1216-1218

Xu K, Saksena P, Fu X, Lei H, Chen N, Carrin G (2009) Health care financing in rural China: New Rural Cooperative Medical Scheme. World Health Organization, Geneva

Yin X, Song F, Gong Y, Tu X, Wang Y, Cao S, Liu J, Lu Z (2013) A systematic review of antibiotic utilization in china. J Antimicrob Chemother 68:2445-2452

Yuan D (2013) A speedy reference for anti-bacterial and anti-inflammation Chinese Medicine: the "natural antibiotics" that you have to know [transl]. Guizhou Science and Technology Publishing House, P.R. China

Zaw Y, Charoenboon N, Haenssgen M, Lubell Y (2018) A comparison of patients' local conceptions of illness and medicines in the context of $\mathrm{C}$-reactive protein biomarker testing in Chiang Rai and Yangon. Am J Trop Med Hyg 98:1661-1670

Zhang D, Unschuld PU (2008) China's barefoot doctor: past, present, and future. Lancet 372:1865-1867

Zhang R, Eggleston K, Rotimi V, Zeckhauser RJ (2006) Antibiotic resistance as a global threat: evidence from China, Kuwait and the United States. Glob Health 2:6

Zhang T, Graham H \& White P (2018) Healthcare providers' accounts of influences of antibiotic-related reforms on their behavior with respect to the use of antibiotics for children: a qualitative study in China. Publ Health Open Access 2(1):000122

Zhao L, Kwiatkowska R, Chai J, Cabral C, Chen M, Bowker K, Coope C, Shen J, Shen X, Chen J, Feng R, Kadetz P, Macgowan A, Oliver I, Hickman M, Wang D, Lambert H (2019). Pathways to optimising antibiotic use in rural China: identifying key determinants in community and clinical settings, a mixed methods study protocol. BMJ Open

Zimmerman F (1982) The jungle and the aroma of meats: an ecological theme in Hindu medicine. University of California Press, Berkeley and Los Angeles

\section{Acknowledgements}

The findings reported in this paper are from a study supported by the Newton Fund, through the UK Medical Research Council (MRC) and the National Natural Science Foundation of China (NSFC). Many thanks to our colleagues Debin Wang (PI), Xingrong Shen, Jing Cheng, Jing Chai, Xuemeng Dong, Maomao Xie and Tao Jiang and in the UK, the other members of our project team for their research contributions and ongoing support. We are especially grateful to all the patients who consented to involvement in the study and to the health care staff who so graciously tolerated the presence of researchers at their places of work over many weeks. Ethical approval for the study was 
granted by the Biomedical Ethics Committee of the collaborating university in China (reference number: 20170271). Participation in the study was fully voluntary and all participants including patients and health care professionals gave informed consent. Geographical references to the research sites have been withheld in order to assure anonymity of local participating healthcare institutions.

\section{Additional information}

Competing interests: The authors declare no competing interests.

Reprints and permission information is available online at http://www.nature.com/ reprints

Publisher's note: Springer Nature remains neutral with regard to jurisdictional claims in published maps and institutional affiliations. (c) (i) Open Access This article is licensed under a Creative Commons Attribution 4.0 International License, which permits use, sharing, adaptation, distribution and reproduction in any medium or format, as long as you give appropriate credit to the original author(s) and the source, provide a link to the Creative Commons license, and indicate if changes were made. The images or other third party material in this article are included in the article's Creative Commons license, unless indicated otherwise in a credit line to the material. If material is not included in the article's Creative Commons license and your intended use is not permitted by statutory regulation or exceeds the permitted use, you will need to obtain permission directly from the copyright holder. To view a copy of this license, visit http://creativecommons.org/ licenses/by/4.0/.

(C) The Author(s) 2019 